\title{
Trading Volume and Firm-Specific Announcements: Implications for the Market Model
}

\author{
John A. Helmuth \\ University of Michigan-Dearborn \\ Ashok J. Robin \\ Rochester Institute of Technology
}

The market model is commonly used in finance to study events and to evaluate security performance. With daily data, it is not uncommon to find low $R$-squares, in the range $0-10 \%$. Prior studies have attempted to improve the fit of the model by excluding observations associated with high trading volume. In this study, we compare the results of the high-volume-exclusion approach with the more direct firm-specific announcement exclusion approach. The announcement approach excludes observations associated with Wall Street Journal Index news items regarding the firm. By excluding the $[-1,0]$ days relative to such news in a sample of 68 firms, we find that $R$-squares increase significantly by about $5 \%$. By excluding the days relative to earnings announcements only, $R$-squares increase by about $4 \%$. These results are then compared to the high-volume-exclusion approach. It is found that this approach is more efficient as an $8 \%$ increase in $R$-squares is produced.

The results of this study provide valuable evidence to empiricists by comparing the two approaches to improving the fit of the market model. The high-volume -exclusion approach provides higher $R$-squares. However, the relative efficiency of the two approaches should be balanced against the arguments for the methodologically correct approach. The advantage of using the firm-specific announcement exclusion approach is that there is more confidence of excluding only firm-specific movements from the estimation of the market model. It also allows a researcher to quickly and unambiguously identify the announcements and delete the

Direct all correspondence to: Ashok J. Robin, Rochester Institute of Technology, College of Business, Roche: ter, NY $14623<$ <ajrbbn@ rit.edu>.

Copyright $\odot 1998$ by JAI Press Inc. 1058-3300 
corresponding observations. Furthermore, we find that about $50 \%$ of the improved fit, relative to the volume approach, can be accomplished by excluding earnings announcements. The methodological disadvantage of using the high-volume-exclusion approach is that it is affected not only by firm-specific announcements but also by other factors, such as the heterogeneity of investor expectations. These factors may influence the choice of using firm-specific announcements rather than the high-volume approach despite the lower increment in $R$-squares.

\section{Introduction}

The market model is a linear time-series model where the dependent variable, security returns, is regressed against percentage changes in a market index. This model captures the market-related movement of a security. The error term, by definition, captures firm-specific movements. If such movements are large, the market model provides poor $R$-squares. With daily data, $R$-squares in the range 0 $10 \%$ is not uncommon. This creates problems in applications of the market model such as tests of efficiency and evaluation of events by not providing enough power in statistical tests. To alleviate this problem, researchers have taken into consideration the nature of the error term in the market model, and have tried to reduce the errors by selectively pruning the data of observations contributing high levels of firm-specific movements.

In earlier attempts to improve the $R$-squares of the market model, principally Cornell (1991) and Robin (1993), high trading volume was used as an indicator of firm-specific movements. By selectively removing observations with high trading volume, it was demonstrated that the $R$-squares can increase by as much as $10 \%$ on a relative basis. That is, an $R$-squares of $10 \%$ could be expected to increase to $11 \%$. In a related study, Graham, Pirie, and Powell (1996) study the implications of this strategy for the power of statistical tests.

In this study, we compare the results of the high-volume-exclusion approach with the more direct firm-specific announcement exclusion approach. This alternative approach is attributable to Roll (1988) who suggests that empiricists exclude observations from days with firm-specific announcements. A comparison of the two approaches has not been addressed by the prior literature because studies have focused on one method or the other. Moreover, the use of firm-specific announcements has not been addressed beyond the exploratory work of Roll (1988).

The analysis of firm-specific announcements in this paper focuses on the regularly scheduled announcements of quarterly earnings and dividends. There are two reasons for this focus. First, it is well known that earnings and dividends announcements are key events contributing to firm-specific security price movements. An extensive literature in finance and accounting has documented this phenomenon; in the area of dividends a synthesis can be found in Denis, Denis and Sarin (1994) and in earnings see Bamber(1987). Second, this allows a researcher to quickly and unambiguously identify the announcements and delete the corresponding observations while running the market model. 
This article provides valuable evidence to empiricists by relatively comparing the two approaches to improving the fit of the market model. Furthermore, the relative efficiency of the approaches should be balanced against the arguments for the methodologically proper approach. The advantage of using explicit announcements rather than trading volume is that one is more confident of excluding firmspecific movements from the estimation of the market model. The disadvantage of using trading volume is that it is affected not only by firm-specific announcements but also by other factors such as the heterogeneity of investor expectations. These factors may influence the choice of using firm-specific announcements rather than high-volume approach despite the lower increment in $R$-squares.

\section{Background}

The market model is given by the linear time-series model:

$$
R_{j t}=a_{j}+b_{j} R_{m t}+e_{j t}
$$

where the time series of firm returns $R_{j t}$ are regressed against the returns on a market index $R_{m t}$. The main application of the market model is in event studies (e.g., Fama, Fisher, Jensen, and Roll, 1969). The objective of event studies is to isolate the security returns attributable to a specific event; to do so, a theoretical/ statistical model is used to generate expected returns or normal returns so that the unexpected returns attributable to a specified event is isolated. The market model is one such model used to generate these benchmark returns so that the unexpected returns (also called abnormal returns) can be inferred. Various tests are performed on these abnormal returns as outlined in Dodd and Warner (1983).

This study relates to the important issue of generating the expected or normal returns in such event studies. The market model is better specified by eliminating the observations containing firm-specific noise in firm returns. This would provide the following benefits: the risk parameter $\beta_{j}$ would be more accurately calculated, and the $R$-squares of the model would be improved. Therefore, statistical tests would also be more powerful.

Roll (1988) first proposed the idea that $R$-squares could be improved by eliminating observations coincident with firm-specific announcements. To put this idea in practice, Roll ran two sets of regressions for 96 large firms. In the first set, all observations-daily data from September 1982 to August 1987-were used to run the Market model regression. In the second set, days on which the Dow-Jones News Retrieval System reported information about the firm are excluded. He concludes that the $R$-squares from the two sets of regressions are similar and that his results "seem to imply the existence of either private information or else occasional frenzy unrelated to concrete information." Since this was a minor part of a paper focusing on the overall problem of poor $R$-squares, Roll did not pursue statistical tests on differences in $R$-squares, nor did he explore the impact of different types of announcements.

Cornell (1990) makes the argument that many press releases made by wellknown firms are non-informative either because they are unimportant or because 
they were previously anticipated. Besides, not all firm-specific information is adequately captured by new items in the Dow Jones database. To circumvent these problems, Cornell argues for the use of volume data to weed out observations involving firm-specific information. Karpoff (1987) notes that volume is commonly understood to proxy for a variable that can be interpreted as information flow. Karpoff summarizes a body of literature that finds empirical support for the presumption that volume and information flows are correlated. This evidence is particularly evident in the accounting literature, where studies (e.g., Bamber, 1987) report that the volume of trading in a company's stock, relative to total market volume, rises in the period immediately surrounding earnings announcements when the rate of information flow is high.

Cornell (1990), therefore, obtains volume information on five large firms from Compuserve for the period 1984 to 1986 . He follows Roll's methodology with the change that observations are now eliminated based on volume. He presents results using all 759 days and with $25,50,75 \ldots$ to 200 high volume days excluded. He finds that in general the $R$-squares improve by about $10 \%$, and improves on Roll (1988) by showing that this improvement is statistically significant. Moreover, he finds that the residual square (the noise in the regression) is directly related to a relative measure of trading volume for each of the five stocks. Robin (1993) extends the results of Cornell by using volume data from the CRSP files on 4,625 securities over the period 1988-1990. Elimination of high volume observations was found to increase $R$-squares by about $10 \%$, confirming results previously reported in Cornell (1990). Further, Robin indicates that this improvement is possible by eliminating a small number of high trading volume observations.

The objective of this study is to compare the results of the high-volumeexclusion approach with Roll's firm-specific announcement exclusion approach. Additionally, we focus more directly on the sources of firm-specific announcements by specifying dividends and earnings announcements, as well as, all firm specific announcements. In this fashion we can isolate the major categories of announcements that will effect the fit of the market model. In its focus on public information flows, this study relates to papers such as Thompson, Olsen, and Dietrich (1987), Berry and Howe (1994) and Palmon, Sun, and Tang (1994). These studies have focused on public information flows (as contrasted with private information flows) and demonstrate the link between trading volume and such information flows. Complementing the focus in these prior studies, in this study, we focus on the link between public information flows and the $R$-squares of the market model.

\section{Sample and Descriptive Statistics}

The CRSP NYSE/ASE files were accessed to obtain returns data and trading volume data for a random sample of 100 firms listed on the database from January 1, 1990 to December 31, 1992. The data were screened to eliminate firms that (a) do not have at least 8 earnings announcements available on the WSJ index, (b) do not have at least 500 non-missing return and trading volume 
Table 1. Description of the Sample

\begin{tabular}{llrrrr}
\hline Variable & $N$ & \multicolumn{1}{c}{ Mean } & \multicolumn{1}{c}{ Std } & \multicolumn{1}{c}{ Min } & \multicolumn{1}{c}{ Max } \\
\hline A. Sample: & & & & & \\
Size & 68 & 867 & 1648 & 17 & 8793 \\
$N$ (time-series) & 68 & 739 & 51 & 512 & 760 \\
$R^{2}$ & 68 & $8.70 \%$ & $8.92 \%$ & $-0.12 \%$ & $39.51 \%$ \\
$\beta$ & 68 & 0.79 & 0.44 & -0.35 & 2.00 \\
$\sigma$ (Returns) & 68 & $2.98 \%$ & $2.47 \%$ & $0.89 \%$ & $14.83 \%$ \\
Volume & 68 & 84349 & 117802 & 2884 & 672428
\end{tabular}

B. All Eligible NYSE/ASE firms:

\begin{tabular}{lrrrrr} 
Size & 2125 & 1385 & 4056 & 1 & 62582 \\
$N$ (time-series) & 2125 & 721 & 67 & 500 & 760 \\
$R^{2}$ & 2125 & $8.50 \%$ & $9.48 \%$ & $-0.20 \%$ & $53.99 \%$ \\
$\beta$ & 2125 & 0.73 & 0.49 & -1.41 & 4.49 \\
$\sigma$ (Returns) & 2125 & $2.94 \%$ & $2.50 \%$ & $0.56 \%$ & $31.16 \%$ \\
Volume & 2125 & 99889 & 183217 & 240 & 1967244 \\
\hline
\end{tabular}

Notes: 1. Sample: The CRSP NYSE/ASE files are used to identify firms that are listed over the period 1990-92. Of these eligible firms, 100 are randomly chosen; the WSJ Index is used to obtain earnings announcement dates for these firms. The final sample of 68 firms meets the further constraint of at least 8 earnings announcement dates during the period 1990-92.

2. Variables: $R^{2}$ is the adjusted $R$-squares, and $\beta$ the slope coefficient from the market model regression using the CRSP value-weighted index. The estimation period is the entire $90-92$ period containing a maximum of 760 daily observations.Size is calculated as price times number of shares at the beginning of this period. Volume denotes trading volume as listed in the CRSP.

3. Analysis: Descriptive statistics are produced.

observations $^{1}$ and (c) do not have data available for the calculation of firm size. The second constraint mitigates the thin trading problem discussed in Scholes and Williams (1977). Dividend announcement dates are obtained from the CRSP database. The final sample contained 68 firms. Most of the firms eliminated were financial firms and funds, principally for failing to meet constraint (a).

Key variables describing this sample are displayed in Table 1. These variables are: number of observations available during the three year period studied, firm size, average trading volume, beta, $R$-squares, and the standard deviation of returns. Firm size was calculated as share price multiplied by number of shares outstanding; these values were obtained as early as possible in the data window of 1990-92. Consequently, for most firms in the sample, firm value indicates market capitalization as of January 2, 1990. The market model is estimated using the CRSP value-weighted index to produce betas.

During the period 1990-92, out of a possible 760 daily observations, the sample of 68 firms had an average of 739 observations. Though the source of the reduction from 760 observations is not reported here, it is noted that this reduction is largely attributable to the requirement of non-missing trading volume. In comparison, as noted in Panel B, the number of observations available for the overall sample of 2,125 NYSE/ASE firms meeting criteria (b-c) is 721. The average beta 
for the sample is 0.79 compared to the overall average of 0.73 and does not appear to be different. The average firm size is 866 million compared to the overall average of 1,385 million. It might appear that the sample firms are smaller than the average firm. However, note that firm size is a highly skewed number. Our sample of 68 firms appears smaller simply because we have not picked up some of the large firms. For instance, the largest firm in the sample has a size of $8,793 \mathrm{com}$ pared to the largest firm in the overall sample, which has a size of 62,581 .

Average trading volume for the sample is 84,349 compared to the overall average of 99,888 . This difference is consistent with the difference in the size numbers. The standard deviation of returns is $2.98 \%$ compared to the overall average of $2.94 \%$. The average market model $R$-squares for the 68 firms is $8.70 \%$ compared to the overall average of $8.50 \%$. Thus, we conclude that the sample of 68 firms appears to be roughly representative of the overall population of NYSE/ ASE firms.

\section{Results}

\section{Replicating Earlier Results}

First, we attempted to replicate the results of Robin (1993) with our sample. Table 2 indicates these results. We find results consistent with the earlier study. Using deletions of $16,32 \ldots .96$ observations having the highest absolute trading volume, we find a pattern of increasing $R$-squares. Much of the increase in $R$-squares occurs on deleting 16 high trading volume observations. The $R$-squares increases from $8.70 \%$ to $9.21 \%$ by deleting 16 observations. The next stage, the deletion of 32 observations, increases $R$-squares further to 9.33\%; this represents a cumulative increase (measured in relative percentage terms) in $R$-squares of roughly $7 \%$. After this, however, the increase in $R$ squares is marginal with the highest $R$-squares of $9.48 \%$ attained by deleting 96 observations. This highest value of $R$-squares represents an increase of about $10 \%$. We also find that the increase in $R$-squares is statistically significant. For example, the deletion of 16 observations indicates that $R$-squares increase with a $t$-statistic of 4.47 . These results are comparable to Robin who reports a $8 \%$ increase in $R$-squares in his sample of 4,087 firms by deleting 30 (out of 758) observations.

\section{Earnings Announcements}

Table 3 reports the main results of this study. For the sample of 68 firms, the $[-1,0]$ days relative to WSJ earnings announcement were excluded from the data set to determine the increase in $R$-squares. Table 3 reports the effects of this deletion on $R$-squares as well as average trading volume and the standard deviation of returns. The $R$-squares increases from $8.70 \%$ to $9.08 \%$. In relative percentage terms, this represents roughly a $4 \%$ increase in $R$-squares. This increase is also statistically significant as: (1) in 42 out of 68 cases, the $R$-squares increased, and (b) the difference in $R$-squares has a $t$-statistic of 3.58 which is significant at the $1 \%$ level. 
Table 2. $R$-squares Improvement from

Excluding High (Absolute) Volume Observations

\begin{tabular}{lccccccc}
\hline Data & $R^{2}$ & $R^{2}-$ Min & $R^{2}-$ Max & $\Delta R^{2}$ & $\Delta R^{2} \%$ & $t$ & Vol \\
\hline Full Set & $8.70 \%$ & $-0.12 \%$ & $39.51 \%$ & $\mathrm{n} / \mathrm{a}$ & $\mathrm{n} / \mathrm{a}$ & $\mathrm{n} / \mathrm{a}$ & 84347 \\
-16 & $9.21 \%$ & $-0.13 \%$ & $42.26 \%$ & $0.51 \%$ & $5.81 \%$ & 4.47 & 76459 \\
-32 & $9.33 \%$ & $-0.14 \%$ & $43.80 \%$ & $0.12 \%$ & $1.36 \%$ & 1.80 & 72491 \\
-48 & $9.42 \%$ & $-0.14 \%$ & $45.36 \%$ & $0.08 \%$ & $0.89 \%$ & 1.14 & 69443 \\
-64 & $9.43 \%$ & $-0.15 \%$ & $46.09 \%$ & $0.02 \%$ & $0.16 \%$ & 0.28 & 66891 \\
-80 & $9.42 \%$ & $-0.21 \%$ & $46.19 \%$ & $-0.01 \%$ & $-0.13 \%$ & -0.23 & 64633 \\
-96 & $9.48 \%$ & $-0.22 \%$ & $45.80 \%$ & $0.06 \%$ & $0.67 \%$ & 1.07 & 62594
\end{tabular}

Notes: 1. Sample: The CRSP NYSE/ASE files are used to identify firms that are listed over the period 1990-92. Of these eligible firms, 100 are randomly chosen; the WSJ Index is used to obtain earnings announcement dates for these firms. The final sample of 68 firms meets the further constraint of at least 8 earnings announcement dates during the period $1990-92$.

2. Variables: $R^{2}$ is the adjusted $R$-squares from the market model regression using the CRSP value-weighted index. The estimation period is $1990-92$. Vol refers to average trading volume

3. Analysis: Market model regressions using the CRSP value-weighted index are run for the sample of 68 firms over the period 1990-92. The impact of deleting the highest trading volume observations (in turn, $16,32, \ldots$ 96 observations to be deleted) out of the total of 760 observations is studied. Sequential data deletions and their impact on $R$-squares is captured in $\Delta R^{2}$ and $\Delta R^{2} \%$. The $t$-statistic for this change in also displayed.

Table 3 also gives us a better understanding of the circumstances under which this increase in $R$-squares takes place. We find that the earnings announcement observations coincide with above average trading volume. The trading volume for all days is 84,349 . However, the average volume for the excluded days is 124,544. In fact, when the earnings relative days were excluded, in 56 out of 68 cases, the average trading volume declined. The 12 cases where the volume did not decrease is interesting because, in 7 of them, the $R$-squares did not improve. Thus we find a strong indication that both high trading volume days and earnings announcement days degrade the performance of the market model.

We also find that the earnings days exclusion decreased the standard deviation of returns for the sample. For all observations, the average standard deviation of returns is $2.98 \%$. By excluding earnings related days, the standard deviation of returns decreases to $2.94 \%$. The excluded days, themselves, have a standard deviation of returns of $3.83 \%$.

To evaluate the sensitivity of these results, the earnings exclusion period was increased to 4 days from 2 days. These results are reported in Panel B of Table 3. The $R$-squares increases from $8.70 \%$ to $9.12 \%$. This increase is also statistically significant as: (1) in 40 out of 68 cases, the $R$-squares increased, and (b) the difference in $R$-squares has a $t$-statistic of 3.35 which is significant at the $1 \%$ level. In general, we find that increasing the interval to 4 days leads to an insignificant increase in $R$-squares and shows the majority of the firm-specific movements for an earnings announcement are contained within two days of the announcement.

\section{Dividend Announcements}

Table 4 shows analogous results where dividend announcements are used instead of earnings announcements. Panel A indicates the impact of excluding the 
Table 3. Improving $R$-squares by Eliminating Earnings Announcements

\begin{tabular}{lrrrrr}
\hline Variable & Mean & Std. Dev. & \multicolumn{1}{l}{ Min } & Max \\
\hline A. Effect of deleting [-1, 0] & observations: & & & \\
Size & 867 & 1648 & $\mathrm{n} / \mathrm{a}$ & 17 & 8793 \\
$\mathrm{~N}-F$ & 739 & 51 & $\mathrm{n} / \mathrm{a}$ & 512 & 760 \\
$\mathrm{~N}-R$ & 716 & 50 & $\mathrm{n} / \mathrm{a}$ & 493 & 738 \\
$R^{2}-F$ & $8.70 \%$ & $8.92 \%$ & $\mathrm{n} / \mathrm{a}$ & $-0.12 \%$ & $39.51 \%$ \\
$R^{2}-R$ & $9.08 \%$ & $9.18 \%$ & $\mathrm{n} / \mathrm{a}$ & $-0.15 \%$ & $40.05 \%$ \\
Volume- $F$ & 84349 & 117802 & $\mathrm{n} / \mathrm{a}$ & 2884 & 672428 \\
Volume- $R$ & 83049 & 115577 & $\mathrm{n} / \mathrm{a}$ & 2683 & 649563 \\
$\sigma$ (returns)-F & $2.98 \%$ & $2.47 \%$ & $\mathrm{n} / \mathrm{a}$ & $0.89 \%$ & $14.83 \%$ \\
$\sigma$ (returns)- $R$ & $2.94 \%$ & $2.46 \%$ & $\mathrm{n} / \mathrm{a}$ & $0.88 \%$ & $14.85 \%$ \\
$\sigma$ (returns)-Ex & $3.83 \%$ & $2.97 \%$ & $\mathrm{n} / \mathrm{a}$ & $0.88 \%$ & $16.27 \%$ \\
Volume-Ex & 124554 & 195939 & $\mathrm{n} / \mathrm{a}$ & 3411 & 1373604 \\
Volume-Diff & -1299 & 2970 & -3.61 & -22865 & 743 \\
$R^{2}$-Diff & $0.38 \%$ & $0.87 \%$ & 3.58 & $-1.49 \%$ & $3.87 \%$
\end{tabular}

B. Effect of deleting $[-3,0]$ observations:

$\begin{array}{lrrrrr}\text { Size } & 867 & 1648 & \mathrm{n} / \mathrm{a} & 17 & 8793 \\ N-F & 739 & 51 & \mathrm{n} / \mathrm{a} & 512 & 760 \\ N-R & 694 & 49 & \mathrm{n} / \mathrm{a} & 480 & 724 \\ R^{2}-F & 8.70 \% & 8.92 \% & \mathrm{n} / \mathrm{a} & -0.12 \% & 39.51 \% \\ R^{2}-R & 9.12 \% & 9.33 \% & \mathrm{n} / \mathrm{a} & -0.15 \% & 41.55 \% \\ \text { Volume- } F & 84349 & 117802 & \mathrm{n} / \mathrm{a} & 2884 & 672428 \\ \text { Volume- } R & 82977 & 115447 & \mathrm{n} / \mathrm{a} & 2677 & 651416 \\ \sigma \text { (retums)- } F & 2.98 \% & 2.47 \% & \mathrm{n} / \mathrm{a} & 0.89 \% & 14.83 \% \\ \sigma \text { (returns)- } R & 2.94 \% & 2.47 \% & \mathrm{n} / \mathrm{a} & 0.88 \% & 14.90 \% \\ \sigma \text { (retums)-Ex } & 3.44 \% & 2.54 \% & \mathrm{n} / \mathrm{a} & 0.81 \% & 13.64 \% \\ \text { Volume-Ex } & 104931 & 155856 & \mathrm{n} / \mathrm{a} & 4100 & 984094 \\ \text { Volume-Diff } & -1371 & 3105 & -3.64 & -21012 & 2056 \\ R^{2} \text {-Diff } & 0.42 \% & 1.02 \% & 3.35 & -1.24 \% & 4.39 \%\end{array}$

Notes: 1. Sample: The CRSP NYSE/ASE files are used to identify firms that are listed over the period 1990-92. Of these eligible firms, 100 are randomly chosen; the WSJ Index is used to obtain earnings announcement dates for these firms. The final sample of 68 firms meets the further constraint of at least 8 earnings announcement dates during the period 1990-92.

2. Variables: $R^{2}$ is the adjusted $R$-squares from the market model regression using the CRSP value-weighted index. The estimation period is $1990-92$. Vol refers to average trading volume; $N$ the number of daily observations, $R^{2} ; \sigma$ is the standard deviation of returns; Size is the market value of equity at the beginning of the period.

3. Analysis: Market model regressions using the CRSP value-weighted index are estimated for the 68 firms during $90-92$ using the full set $(F)$ of 760 observations as well as the reduced set $(R)$ where the $[-1,0]$ (Panel A) or $[-3,0]$ (Panel B) observations related to earnings announcements have been deleted. $T$-statistics are reported for the difference (labeled 'Diff') between the ' $F$ ' and ' $R$ ' data-sets with respect to the trading volume and $R^{2}$ from the market model. $\sigma$ (returns) and volume are also reported for the excluded observations (labeled ' $E x$ ').

$[-1,0]$ days relative to the dividend announcements as listed on the CRSP files. The $R$-squares increases from $8.70 \%$ to $8.71 \%$. This change is not statistically significant. The $t$-statistic for the change is 0.17 . Further the $R$-squares increases only in 22 out of 68 cases.

The trading volume for all days is 84,349 and that for days excluding announcements is 84,264 . Only in 21 of 68 cases does the volume decrease. The 
Table 4. Improving $R$-squares by Eliminating Dividends Announcements

\begin{tabular}{|c|c|c|c|c|c|}
\hline & Mean & Std. Dev. & $t$ & $\operatorname{Min}$ & Max \\
\hline \multicolumn{6}{|c|}{ A. Effect of deleting $[-1,0]$ observations: } \\
\hline Size & 867 & 1648 & $\mathrm{n} / \mathrm{a}$ & 17 & 8793 \\
\hline$N-F$ & 739 & 51 & $\mathrm{n} / \mathrm{a}$ & 512 & 760 \\
\hline$N-R$ & 724 & 49 & $\mathrm{n} / \mathrm{a}$ & 512 & 760 \\
\hline$R^{2}-F$ & $8.70 \%$ & $8.92 \%$ & $\mathrm{n} / \mathrm{a}$ & $-0.12 \%$ & $39.51 \%$ \\
\hline$R^{2}-R$ & $8.71 \%$ & $9.02 \%$ & $\mathrm{n} / \mathrm{a}$ & $-0.12 \%$ & $40.35 \%$ \\
\hline Volume- $F$ & 84349 & 117802 & $\mathrm{n} / \mathrm{a}$ & 2884 & 672428 \\
\hline Volume- $R$ & 84264 & 117379 & $\mathrm{n} / \mathrm{a}$ & 2893 & 667905 \\
\hline$\sigma$ (returns)- $F$ & $2.98 \%$ & $2.47 \%$ & $\mathrm{n} / \mathrm{a}$ & $0.89 \%$ & $14.83 \%$ \\
\hline$\sigma$ (returns)- $R$ & $2.98 \%$ & $2.47 \%$ & $\mathrm{n} / \mathrm{a}$ & $0.89 \%$ & $14.83 \%$ \\
\hline$\sigma$ (returns)-Ex & $1.98 \%$ & $0.83 \%$ & $\mathrm{n} / \mathrm{a}$ & $0.61 \%$ & $4.73 \%$ \\
\hline Volume-Ex & 95866 & 153976 & $\mathrm{n} / \mathrm{a}$ & 2553 & 811129 \\
\hline Volume-Diff & -85 & 929 & -0.75 & -4523 & 2128 \\
\hline$R^{2}$-Diff & $0.01 \%$ & $0.27 \%$ & 0.17 & $-0.68 \%$ & $0.84 \%$ \\
\hline
\end{tabular}

B. Effect of deleting $[-3,0]$ observations:

$\begin{array}{lrrrrr}\text { Size } & 867 & 1648 & \mathrm{n} / \mathrm{a} & 17 & 8793 \\ N-F & 739 & 51 & \mathrm{n} / \mathrm{a} & 512 & 760 \\ N-R & 709 & 49 & \mathrm{n} / \mathrm{a} & 512 & 760 \\ R^{2}-F & 8.70 \% & 8.92 \% & \mathrm{n} / \mathrm{a} & -0.12 \% & 39.51 \% \\ R^{2}-R & 8.73 \% & 9.10 \% & \mathrm{n} / \mathrm{a} & -0.12 \% & 40.09 \% \\ \text { Volume- } F & 84349 & 117802 & \mathrm{n} / \mathrm{a} & 2884 & 672428 \\ \text { Volume- } R & 84083 & 116153 & \mathrm{n} / \mathrm{a} & 2880 & 650193 \\ \sigma \text { (returns)- } F & 2.98 \% & 2.47 \% & \mathrm{n} / \mathrm{a} & 0.89 \% & 14.83 \% \\ \sigma \text { (returns)- } R & 2.98 \% & 2.47 \% & \mathrm{n} / \mathrm{a} & 0.90 \% & 14.83 \% \\ \sigma \text { (returns)-Ex } & 1.95 \% & 0.68 \% & \mathrm{n} / \mathrm{a} & 0.68 \% & 3.58 \% \\ \text { Volume-Ex } & 97718 & 171280 & \mathrm{n} / \mathrm{a} & 2958 & 1002244 \\ \text { Volume-Diff } & -265 & 2956 & -0.74 & -22235 & 3157 \\ R^{2} \text {-Diff } & 0.03 \% & 0.54 \% & 0.50 & -1.11 \% & 2.58 \%\end{array}$

Notes: 1. Sample: The CRSP NYSE/ASE files are used to identify firms that are listed over the period 1990-92. Of these eligible firms, 100 are randomly chosen; the WSJ Index is used to obtain earnings announcement dates for these firms. The final sample of 68 firms meets the further consuraint of at least 8 earnings announcement dates during the period 1990-92.

2. Variables: $R^{2}$ is the adjusted $R$-squares from the market model regression using the CRSP value-weighted index. The estimation period is $1990-92$. Vol refers to average trading volume: $N$ the number of daily observations, $R^{2} ; \sigma$ is the standard deviation of returns; Size is the market value of equity at the beginning of the period.

3. Analysis: Market model regressions using the CRSP value-weighted index are estimated for the 68 firms during $90-92$ using the full set $(F)$ of 760 observations as well as the reduced set $(R)$ where the $[-1,0]$ (Panel $\mathrm{A}$ ) or $[-3,0]$ (Panel B) observations related to dividend announcements have been deleted. $T$-statistics are reported for the difference (labeled 'Diff') between the ' $F$ ' and ' $R$ ' data-sets with respect to the trading volume and $R^{2}$ from the market model. s(returns) and volume are also reported for the excluded observations (labeled 'Ex').

trading volume for the announcement days is 95,866 . Unlike the case of earnings announcements, dividend announcements do not appear to engender abnormal trading volume. The result for standard deviation of returns is also similar. The exclusion of dividend announcement days serves to keep the standard deviation steady at $2.98 \%$. The standard deviation for the announcement days is actually lower at $1.98 \%{ }^{2}$ 
Table 5. Improving $R$-squares by Eliminating $[-1,0]$ Observations for all WSJ Announcements

\begin{tabular}{lrrrrr}
\hline & Mean & Std. Dev. & \multicolumn{1}{c}{$t$} & \multicolumn{1}{c}{ Min } & \multicolumn{1}{c}{ Max } \\
\hline Size & 867 & 1648 & $\mathrm{n} / \mathrm{a}$ & 17 & 8793 \\
$N-F$ & 739 & 51 & $\mathrm{n} / \mathrm{a}$ & 512 & 760 \\
$N-R$ & 684 & 53 & $\mathrm{n} / \mathrm{a}$ & 475 & 734 \\
$R^{2}-F$ & $8.70 \%$ & $8.92 \%$ & $\mathrm{n} / \mathrm{a}$ & $-0.12 \%$ & $39.51 \%$ \\
$R^{2}-R$ & $9.18 \%$ & $9.43 \%$ & $\mathrm{n} / \mathrm{a}$ & $-0.14 \%$ & $45.52 \%$ \\
Volume- $F$ & 84349 & 117802 & $\mathrm{n} / \mathrm{a}$ & 2884 & 672428 \\
Volume- $R$ & 81542 & 113372 & $\mathrm{n} / \mathrm{a}$ & 2535 & 644193 \\
$\sigma$ (returns)- $F$ & $2.98 \%$ & $2.47 \%$ & $\mathrm{n} / \mathrm{a}$ & $0.89 \%$ & $14.83 \%$ \\
$\sigma$ (returns)- $R$ & $2.89 \%$ & $2.38 \%$ & $\mathrm{n} / \mathrm{a}$ & $0.88 \%$ & $13.70 \%$ \\
$\sigma$ (returns)-Ex & $3.93 \%$ & $3.86 \%$ & $\mathrm{n} / \mathrm{a}$ & $0.86 \%$ & $26.84 \%$ \\
Volume-Ex & 113087 & 149782 & $\mathrm{n} / \mathrm{a}$ & 4856 & 882619 \\
Volume-Diff & -2807 & 5829 & -3.97 & -34613 & 260 \\
$R^{2}$-Diff & $0.48 \%$ & $1.35 \%$ & 2.91 & $-4.37 \%$ & $6.01 \%$ \\
\hline
\end{tabular}

Notes: 1. Sample: The CRSP NYSE/ASE files are used to identify firms that are listed over the period 1990-92. Of these eligible firms, 100 are randomly chosen; the WSJ Index is used to obtain earnings announcement dates for these firms. The final sample of 68 firms meets the further constraint of at least 8 earnings announcement dates during the period 1990-92.

2. Variables: $\boldsymbol{R}^{2}$ is the adjusted $\boldsymbol{R}$-squares from the market model regression using the CRSP value-weighted index. The estimation period is $1990-92$. $V o l$ refers to average trading volume; $N$ the number of daily observations, $R^{2} ; \sigma$ is the standard deviation of returns: Size is the market value of equity at the beginning of the period.

3. Analysis: Market model regressions using the CRSP value-weighted index are estimated for the 68 firms during $90-92$ using the full set $(F)$ of 760 observations as well as the reduced set $(R)$ where the $[-1,0]$ (Panel A) or $[-3,0]$ (Panel B) observations related to all WSJ Index announcements have been deleted. $T$-statistics are reported for the difference (labeled 'Diff') between the ' $F$ ' and ' $R$ ' data-sets with respect to the trading volume and $R^{2}$ from the market model. s(returns) and volume are also reported for the excluded observations (labeled 'Ex').

To evaluate the sensitivity of these results, the dividend exclusion period was increased to 4 days from 2 days. These results are reported in Panel B of Table 4. The $R$-squares increases from $8.70 \%$ to $8.73 \%$. This change is not statistically significant. The $t$-statistic for the change is 0.50 . Further the $R$-squares increases only in 19 out of 68 cases. As with earnings, we find that increasing the interval for dividends does not materially affect the results.

\section{All WSJ Index News Items}

We now turn to tests of the (WSJ Index) universe of firm announcements. Instead of confining attention to earnings and dividend announcements, we now consider all announcements including mergers and acquisition news, product news, discussion of earnings, etc. Arguably, these items would capture firm-specific information to a greater extent, thereby increasing the $R$-squares further. Table 5 reports these additional results.

For the sample of 68 firms, the exclusion of $[-1,0]$ days relative to all WSJ earnings announcement increases the $R$-squares from $8.70 \%$ to $9.18 \%$. In relative percentage terms, this represents roughly a $1.48 \%$ increase in $R$-squares. This increase is statistically significant as: (1) in 44 out of 68 cases the $R$-squares increase, and (b) the difference in $R$-squares has a $t$-statistic of 2.91 . Consistent 
Table 6. Improving $R$-squares by Excluding Extreme Return Observations $(N=68)$

\begin{tabular}{lrrrrr}
\hline & Mean & Std.. Dev. & \multicolumn{1}{c}{$t$} & Min & \multicolumn{1}{c}{ Max } \\
\hline Size & 867 & 1648 & $\mathrm{n} / \mathrm{a}$ & 17 & 8793 \\
$N-F$ & 739 & 51 & $\mathrm{n} / \mathrm{a}$ & 512 & 760 \\
$N-R$ & 726 & 50 & $\mathrm{n} / \mathrm{a}$ & 502 & 746 \\
$R^{2}-F$ & $8.70 \%$ & $8.92 \%$ & $\mathrm{n} / \mathrm{a}$ & $-0.12 \%$ & $39.51 \%$ \\
$R^{2}-R$ & $8.05 \%$ & $8.42 \%$ & $\mathrm{n} / \mathrm{a}$ & $-0.12 \%$ & $37.74 \%$ \\
Volume- $F$ & 84349 & 117802 & $\mathrm{n} / \mathrm{a}$ & 2884 & 672428 \\
Volume- $R$ & 82146 & 115056 & $\mathrm{n} / \mathrm{a}$ & 2685 & 658187 \\
O(returns)-F & $2.98 \%$ & $2.47 \%$ & $\mathrm{n} / \mathrm{a}$ & $0.89 \%$ & $14.83 \%$ \\
$\sigma$ (returns)- $R$ & $2.59 \%$ & $2.11 \%$ & $\mathrm{n} / \mathrm{a}$ & $0.81 \%$ & $12.32 \%$ \\
O (returns)-Ex & $11.14 \%$ & $9.83 \%$ & $\mathrm{n} / \mathrm{a}$ & $2.92 \%$ & $65.87 \%$ \\
Volume-Ex & 201498 & 277226 & $\mathrm{n} / \mathrm{a}$ & 7421 & 1431207 \\
Volume-Diff & -2203 & 3159 & -5.75 & -14240 & 93 \\
$R^{2}$-Diff & $-0.66 \%$ & $1.36 \%$ & -3.97 & $-5.34 \%$ & $2.46 \%$ \\
\hline
\end{tabular}

Notes: 1. Sample: The CRSP NYSE/ASE files are used to identify firms that are listed over the period 1990-92. Of these eligible firms, 100 are randomly chosen; the WSJ Index is used to obtain earnings announcement dates for these firms. The final sample of 68 firms meets the further constraint of at least 8 earnings announcement dates during the period 1990-92.

2. Variables: $R^{2}$ is the adjusted $R$-squares from the market model regression using the CRSP value-weighted index. The estimation period is $1990-92$. Vol refers to average trading volume; $N$ the number of daily observations, $R^{2} ; \sigma$ is the standard deviation of retums; Size is the market value of equity at the beginning of the period.

3. Analysis: Market model regressions using the CRSP value-weighted index are estimated for the 68 firms during $90-92$ using the full set $(F)$ of 760 observations as well as the reduced set $(R)$ where the top and bottom $1 \%$ of security returns have been deleted. $T$-statistics are reported for the difference (labeled ' $D$ iff') between the ' $F$ ' and ' $R$ ' data-sets with respect to the trading volume and $R^{2}$ from the market model. s(returns) and volume are also reported for the excluded observations (labeled 'Ex').

with these results, Table 5 also indicates that the difference in volume between the full set and the reduced set of observations is significant with a t-statistic of -3.97 .

Comparing these results with those for the earnings exclusion reported in Table 3, we find that there is little or no benefit to resorting to the comprehensive strategy of excluding all WSJ index announcements. This result again reinforces the earlier conclusion that earnings announcements dominate with firm specific security movements.

\section{Extreme Return Observations}

Finally, regressions were run where the top and bottom $1 \%$ of observations were excluded based on the value of firm returns. This was done for two reasons. First, we wanted to check whether the benefits from the above analysis were merely due to the exclusion of "extreme" observations. Such an approach in regression analysis is quite prevalent in the accounting literature, an example being the price-earnings regression analysis in Kothari (1992). The motivation for such a procedure is one of eliminating observations that are most likely erroneous. Since the CRSP returns are relatively clean, this procedure is not expected to substantially change results. The second reason why the extreme observations are excluded is because of the hypothesis that extreme return observations are primarily reflective of firm-specific movements. Empirically such a hypothesis makes sense because observed 'extreme' return changes for individual securities exceed 
by a wide margin the return we would expect conditional on 'extreme' market returns.

Table 6 reports the results for this analysis. Surprisingly, the elimination of 'extreme' returns decreases $R$-squares from $8.7 \%$ to $8.05 \%$. This change is significant with a $t$-statistic of -3.97 . This data exclusion produced an increase in $R$-squares for 19 out of 68 cases. This result is interesting because the other indicators-trading volume and standard deviation of returns-look favorable for increasing $R$-squares. By construction we would expect a reduction in the standard deviation of returns; it decreases from $2.98 \%$ to $2.59 \%$. The standard deviation of the excluded observations is $11.14 \%$. Consistent with the decrease in standard deviation of returns for the 'pruned' sample, volume is also significantly lower; most distinctly this is reflected in the volume of the excluded observations which is 201,498 . The change in volume is also significant as in 68 of 68 cases the volume decreased.

\section{Summary and Conclusion}

This study tries to improve the market model estimation process by excluding observations coincident with firm-specific announcements. Specifically, days related to all announcements in the WSJ Index regarding the firm are excluded from the estimation period. This strategy is shown to significantly increase $R$-squares by about $5 \%$. By excluding the $[-1,0]$ days relative to earnings announcements only, $R$-squares increase by about $4 \%$. The exclusion of dividend announcements has an insignificant result. The above results are then compared to the $R$-squares produced by a high-volume-exclusion approach. It is found that this approach is more efficient as an $8 \%$ increase in $R$-squares is produced.

The results of this article provide valuable evidence to empiricists by comparing the two approaches to improving the fit of the market model. The high-volume -exclusion approach provides higher $R$-squares. However, the relative efficiency of the two approaches should be balanced against the arguments for the methodologically correct approach. The advantage of using the firm-specific announcement exclusion approach is that there is more confidence of excluding only firm-specific movements from the estimation of the market model. It also allows a researcher to quickly and unambiguously identify the announcements and delete the corresponding observations. Furthermore, we find that about $50 \%$ of the improved fit, relative to the volume approach, can be accomplished by excluding earnings announcements. The methodological disadvantage of using the high-volume-exclusion approach is that it is affected not only by firm-specific announcements but also by other factors, such as the heterogeneity of investor expectations. These factors may influence the choice of using firm-specific announcements rather than the high-volume approach despite the lower increment in $R$-squares.

\section{Notes}

1. The observation following a missing observation was also treated as a missing observation to mitigate the problem of non-synchronous trading. 
2. The odd statistics for the announcement days is influenced by the data requirement of at least 10 observations for the calculation of both the standard deviation of returns as well as the average volume. Thus the difference between the 'all observations' case and the 'all except announcement' case is not fully explained by the 'announcement' case. This problem only arises in the case of dividend announcements as some firms had fewer than 10 days.

\section{References}

Bamber, L.S. 1987. Unexpected Earnings, Firm Size and Trading Volume around Quarterly Earnings Announcements. Accounting Review 63: 510-532.

Berry, T., and K. Howe. 1994. Public Information Arrival. Journal of Finance XLIX No.4: 13311346.

Cornell, B. 1990. Volume and $R$-squares: A First Look. Journal of Financial Research 13: 1-6.

Denis, D., D. Denis, and A. Sarin. 1994. The Information Content of Dividend Changes: Cash Flow Signaling, Overinvestment, and Dividend Clienteles. Journal of Financial and Quantitative Analysis 29: 567-587.

Dodd, P., and J. Warner. 1983. On Corporate Governance: A Study of Proxy Contests. Journal of Financial Economics 11: 401-438.

Fama, E., L. Fisher, M. Jensen, and R. Roll. 1969. The Adjustment of Stock Prices to New Information. International Economic Review 10: 1-21.

Graham, S., W. Pirie, and W. Powell. 1996. Detecting Abnormal Returns Using the Market Model with Pre-tested Data. Journal of Financial Research 19.1: 21-40.

Johnston, J. 1984. Econometric Methods. New York: McGraw Hill.

Karpoff, J.M. 1987. The Relation between Price Changes and Volume: A Survey. Journal of Financial and Quantitative Analysis 22: 109-126.

Kothari, S.P. 1992. Price-earnings Regressions in the Presence of Prices Leading Earnings. Journal of Accounting and Economics 15: 173-202.

Lintner, J. 1965. The Valuation of Risk Assets and the Selection of Risky Investments in Stock Portfolios and Capital Budgets. Review of Economics and Statistics 47: 13-37.

Palmon, O., H. Sun, and A. Tang. 1994. The Impact of Publication of Analysts' Recommendations on Returns and Trading Volume. Financial Review 29.3: 395-418.

Robin, A. 1993. On Improving the Performance of the Market Model. Journal of Financial Research 16.4 (Winter): $367-376$.

Roll, R. 1988. $R$-squares. Journal of Finance 43: 541-566.

Scholes, M., and J. Williams. 1977. Estimating Beta from Nonsynchronous Data. Journal of Financial Economics 5: 309-327.

Sharpe, W. 1964. Capital Asset Pricing: A Theory of Market Equilibrium Under Conditions of Risk. Journal of Finance 19: 425-442.

Thompson, R., C. Olsen, and J. Dietrich, 1987. Attributes of News about Firms: An Analysis of Firmspecific News Reported in the Wall Street Journal Index. Journal of Accounting Research 25: 245-274. 